\title{
Management of hard-to-heal diabetic foot ulcers: local use of autologous leucocytes, platelets and fibrin multi-layered patches (LeucoPatch)
}

\author{
Francisco Javier Álvaro-Afonso ${ }^{1}$, Jose Luis Lázaro-Martínez ${ }^{1}$, Yolanda García-Álvarez ${ }^{1}$, Nikolaos Papanas ${ }^{2}$ \\ ${ }^{1}$ Diabetic Foot Unit, Universidad Complutense de Madrid, Instituto de Investigación Sanitaria del Hospital Clínico San Carlos (IdISSC), Madrid, \\ Spain; ${ }^{2}$ Diabetes Centre-Diabetic Foot Clinic, Second Department of Internal Medicine, University Hospital of Alexandroupolis, Democritus \\ University of Thrace, Alexandroupolis, Greece \\ Correspondence to: Prof. Nikolaos Papanas. Diabetes Centre, Second Department of Internal Medicine, G. Kondyli 22c, Alexandroupolis 68100, \\ Greece. Email: papanasnikos@yahoo.gr. \\ Provenance: This is an invited Editorial commissioned by the Section Editor Kaiping Zhang (AME College, AME Group, China). \\ Comment on: Game F, Jeffcoate W, Tarnow L, et al. LeucoPatch system for the management of hard-to-heal diabetic foot ulcers in the UK, Denmark, \\ and Sweden: an observer-masked, randomised controlled trial. Lancet Diabetes Endocrinol 2018;6:870-8.
}

Submitted Dec 11, 2018. Accepted for publication Dec 13, 2018.

doi: $10.21037 / \mathrm{atm} .2018 .12 .44$

View this article at: http://dx.doi.org/10.21037/atm.2018.12.44

Hard-to-heal diabetic foot ulcers (DFUs) represent a clinical challenge for physicians and healthcare systems worldwide. It is estimated that approximately $77 \%$ of DFUs heal within 1 year in specialised tertiary care European hospitals $(1,2)$. DFUs are associated with impoverished quality of life and a high cost for healthcare services (3).

The Wound Healing Society guidelines advocate advanced wound therapies for DFUs, should the latter be not reduced in size by $\geq 40 \%$ following standard therapy for 4 weeks (4). So far, such advanced therapies include negative-pressure wound therapy (5), hyperbaric oxygen therapy (6), ultrasound-assisted debridement (7), new wound dressings $(8,9)$, different types of dermo-epidermal skin substitutes (10), granulocyte-colony stimulating factor (11), as well as autologous stem cells (12).

In this context, a recent multi-centre, international, observer-masked, randomised controlled trial (RCT) by Game et al. (13) has provided favourable results on the use of autologous imnune cell, platelet and fibrin patches (LeucoPatch). This was applied to the surface of the wound in subjects with diabetes and hard-to-heal DFUs (13). The RCT was carried out in 32 specialised diabetic foot clinics in the United Kingdom, Denmark, and Sweden. Patients with a DFU reduction $<50 \%$ after a 4 -week run-in period were randomised to either pre-specified good standard care alone (137 patients) or care plus weekly application of LeucoPatch (132 patients) (13). The primary outcome was the proportion of healing ulcers (defined as complete epithelialisation) within 20 weeks and remained healed for 4 weeks. Forty-five (34\%) of 132 ulcers healed within 20 weeks in the LeucoPatch group vs. 29 (22\%) of 134 ulcers in the standard care group [odds ratio (OR): 1.58, 95\% confidence interval (CI): 1.04-2.40, $\mathrm{P}=0.0235]$ within 20 weeks (13). Median time to healing was 72 days [interquartile range (IQR), 56-103 days] in the LeucoPatch group and 84 days (IQR, 64-98 days) in the standard care group $(\mathrm{P}=0.0343)$, time to healing was shorter up to 12 weeks in the LeucoPatch group than in the standard care group [hazard ratio (HR): 1.709, 95\% CI: 1.071-2.728, $\mathrm{P}=0.0246]$ (13). Major or minor amputations, episodes of clinical infection, antibiotic use or serious events showed no difference between the two treatment arms (13). Importantly, adverse or serious adverse event rates did not differ between the two groups. This holds true for incidence of anaemia in LeucoPatch-treated patients, despite repeated venesection (13).

The RCT by Game et al. (13) has important strengths. First, it focused on hard-to-heal DFUs. Secondly, all investigators offered standard-of-care treatment using prespecified criteria, maintained through regular scientific meetings. Moreover, the target number of participants was finally recruited, and patient retention at the end was very 
high (13-15). A limitation was that it was not possible to mask either the participant or the researcher to treatment allocation, but the primary outcome was assessed by a blinded independent observer and backed up with digital imaging (13).

Unfortunately, there are currently few robust RCTs on care products for DFUs. Platelet preparations have been suggested as adjunctive therapies, but the clinical evidence for their efficacy remains limited and inconsistent $(16,17)$. A previous multi-centre pilot study has shown that the leucocyte patch is well-tolerated, easy to use and holds therapeutic promise (18). Unlike other treatments based on autologous blood, this local therapy has a compact, three-layered structure: a layer with a high concentration of fibrin, a layer of concentrated leucocytes and a layer of concentrated platelet, which exhibit different chemotactic, mitogenic and proliferative properties $(18,19)$. The new RCT (13) has provided strong additional evidence on the efficacy and safety of LeucoPatch.

Nevertheless, it is necessary to perform RCTs for other types of DFUs. Indeed, Game et al. (13) included noninfected DFUs, according to the Infectious Diseases Society of America (20), without critical leg ischaemia. Most DFUs were $>1 \mathrm{~cm}^{2}$, superficial and on the forefoot (13). Moreover, very large DFUs $\left(>10 \mathrm{~cm}^{2}\right)$, those with very marked ischaemia and patients with severe renal disease were excluded (13). These DFU characteristics do not accurately reflect everyday clinical practice. Still, the median number of recruited ulcers in each centre was similar to a recent RCT of another dressing acting on the activity of matrix metalloproteinases (sucrose octasulphate dressing) to accelerate wound healing in patients with neuroischaemic DFUs (Explorer) (8). In the Explorer trial, in contrast to the Leucopatch trial (13), neuroischaemic DFUs were defined by the University of Texas Diabetic Wound Classification system as IC (ischaemic, non-infected superficial wound) or IIC (ischaemic, non-infected wound penetrating to tendon or capsule) and large ulcers were included (1-30 vs. $\left.0.5-10 \mathrm{~cm}^{2}\right)$. In both RCTs, patients received an off-loading device and at wounds were debrided at the investigator's discretion and following the International Working Group of the Diabetic Foot guidelines (21).

We now know that more than half of DFUs become infected (22) and the prevalence of osteomyelitis in DFUs is currently $66.7-70.4 \%$ in specialised diabetic foot units $(23,24)$. Game et al. (13) reported no differences in the incidence of diabetic foot infection between both groups (24 events in the Leucopatch group vs. 20 events in the standard care group). Furthermore, only 3 ulcers (2\%) in the standard of care group and $6(5 \%)$ in the LeucoPatch group penetrated to the bone. A recent case report shows that leucocyte platelet rich fibrin could be useful in the treatment of DFU with osteomyelitis, calling for a dedicated RCT (25).

Based on the study by Game et al. (13), production of LeucoPatch is fast and, and its application is very convenient. Certainly, patient satisfaction was not evaluated, but there were very few dropouts. Moreover, a cost-effectiveness analysis will be required. The optimal treatment duration also needs to be better ascertained. Of note, healing was faster in the intervention group during the first 12 weeks, but not thereafter, tempting us to ponder whether LeucoPatch treatment might be terminated before complete wound closure (13).

In conclusion, the excellent RCT by Game et al. (13) has provided robust evidence in support of a new intervention based on fibrin, autologous immune cell and platelet patches in the management of recalcitrant DFUs. Their results are very promising. Accordingly, experience in other types of DFUs and cost-effectiveness analysis are highly welcome to increase the utility of this product for clinical practice.

\section{Acknowledgements}

None.

\section{Footnote}

Conflicts of Interest: N Papanas has been an advisory board member of TrigoCare International, Abbott, AstraZeneca, Elpen, MSD, Novartis, Novo Nordisk, Sanofi-Aventis and Takeda; has participated in sponsored studies by Eli Lilly, MSD, Novo Nordisk, Novartis and Sanofi-Aventis; received honoraria as a speaker for AstraZeneca, Boehringer Ingelheim, Eli Lilly, Elpen, Galenica, MSD, Mylan, Novartis, Novo Nordisk, Pfizer, Sanofi-Aventis, Takeda and Vianex; and attended conferences sponsored by TrigoCare International, AstraZeneca, Boehringer Ingelheim, Eli Lilly, Novartis, Novo Nordisk, Pfizer and Sanofi-Aventis. The other authors have no conflicts of interest to declare.

\section{References}

1. Prompers L, Schaper N, Apelqvist J, et al. Prediction of outcome in individuals with diabetic foot ulcers: focus on the differences between individuals with and without peripheral arterial disease. The EURODIALE Study. 
Diabetologia 2008;51:747-55.

2. Armstrong DG, Boulton AJM, Bus SA. Diabetic Foot Ulcers and Their Recurrence. N Engl J Med 2017;376:2367-75.

3. García-Morales E, Lazaro-Martinez JL, MartinezHernandez D, et al. Impact of diabetic foot related complications on the Health Related Quality of Life (HRQol) of patients--a regional study in Spain. Int J Low Extrem Wounds 2011;10:6-11.

4. Steed DL, Attinger C, Colaizzi T, et al. Guidelines for the treatment of diabetic ulcers. Wound Repair Regen 2006;14:680-92.

5. Liu S, He CZ, Cai YT, et al. Evaluation of negativepressure wound therapy for patients with diabetic foot ulcers: systematic review and meta-analysis. Ther Clin Risk Manag 2017;13:533-44.

6. Zhao D, Luo S, Xu W, et al. Efficacy and Safety of Hyperbaric Oxygen Therapy Used in Patients With Diabetic Foot: A Meta-analysis of Randomized Clinical Trials. Clin Ther 2017;39:2088-94.e2.

7. Lázaro-Martínez JL, Alvaro-Afonso FJ, Garcia-Alvarez Y, et al. Ultrasound-assisted debridement of neuroischaemic diabetic foot ulcers, clinical and microbiological effects: a case series. J Wound Care 2018;27:278-86.

8. Edmonds M, Lazaro-Martinez JL, Alfayate-Garcia JM, et al. Sucrose octasulfate dressing versus control dressing in patients with neuroischaemic diabetic foot ulcers (Explorer): an international, multicentre, double-blind, randomised, controlled trial. Lancet Diabetes Endocrinol 2018;6:186-96.

9. Edmonds ME, Bodansky HJ, Boulton AJM, et al. Multicenter, randomized controlled, observer-blinded study of a nitric oxide generating treatment in foot ulcers of patients with diabetes-ProNOx1 study. Wound Repair Regen 2018;26:228-37.

10. Santema TB, Poyck PP, Ubbink DT. Systematic review and meta-analysis of skin substitutes in the treatment of diabetic foot ulcers: Highlights of a Cochrane systematic review. Wound Repair Regen 2016;24:737-44.

11. Cruciani M, Lipsky BA, Mengoli C, et al. Granulocytecolony stimulating factors as adjunctive therapy for diabetic foot infections. Cochrane Database Syst Rev 2013:CD006810.

12. Guo J, Dardik A, Fang K, et al. Meta-analysis on the treatment of diabetic foot ulcers with autologous stem cells. Stem Cell Res Ther 2017;8:228.

13. Game F, Jeffcoate W, Tarnow L, et al. LeucoPatch system for the management of hard-to-heal diabetic foot ulcers in the UK, Denmark, and Sweden: an observer-masked, randomised controlled trial. Lancet Diabetes Endocrinol 2018;6:870-8.

14. Jeffcoate WJ, Bus SA, Game FL, et al. Reporting standards of studies and papers on the prevention and management of foot ulcers in diabetes: required details and markers of good quality. Lancet Diabetes Endocrinol 2016;4:781-8.

15. Game F, Jeffcoate W, Tarnow L, et al. The LeucoPatch(R) system in the management of hard-to-heal diabetic foot ulcers: study protocol for a randomised controlled trial. Trials 2017;18:469.

16. Game FL, Apelquist J, Attinger C, et al. Effectiveness of interventions to enhance healing of chronic ulcers of the foot in diabetes: a systematic review. Diabetes Metab Res Rev 2016;32 Suppl 1:154-68.

17. Picard F, Hersant B, Bosc R, et al. The growing evidence for the use of platelet-rich plasma on diabetic chronic wounds: A review and a proposal for a new standard care. Wound Repair Regen 2015;23:638-43.

18. Löndahl M, Tarnow L, Karlsmark T, et al. Use of an autologous leucocyte and platelet-rich fibrin patch on hard-to-heal DFUs: a pilot study. J Wound Care 2015;24:172-4, 176-8.

19. Lundquist R, Holmstrom K, Clausen C, et al. Characteristics of an autologous leukocyte and plateletrich fibrin patch intended for the treatment of recalcitrant wounds. Wound Repair Regen 2013;21:66-76.

20. Lipsky BA, Berendt AR, Cornia PB, et al. 2012 Infectious Diseases Society of America clinical practice guideline for the diagnosis and treatment of diabetic foot infections. Clin Infect Dis 2012;54:e132-73.

21. Bakker K, Apelqvist J, Lipsky BA, et al. The 2015 IWGDF guidance on the prevention and management of foot problems in diabetes. Int Wound J 2016;13:1072.

22. Prompers L, Huijberts M, Apelqvist J, et al. High prevalence of ischaemia, infection and serious comorbidity in patients with diabetic foot disease in Europe. Baseline results from the Eurodiale study. Diabetologia 2007;50:18-25.

23. Álvaro-Afonso FJ, Lázaro-Martínez JL, García-Morales $\mathrm{E}$, et al. Cortical disruption is the most reliable and accurate plain radiographic sign in the diagnosis of diabetic foot osteomyelitis. Diabet Med 2018. [Epub ahead of print].

24. Aragón-Sánchez J, Lipsky BA, Lazaro-Martinez JL. Diagnosing diabetic foot osteomyelitis: is the combination of probe-to-bone test and plain 
radiography sufficient for high-risk inpatients? Diabet Med 2011;28:191-4.

25. Crisci A, Marotta G, Licito A, et al. Use of Leukocyte

Cite this article as: Álvaro-Afonso FJ, Lázaro-Martínez JL, García-Álvarez Y, Papanas N. Management of hard-to-heal diabetic foot ulcers: local use of autologous leucocytes, platelets and fibrin multi-layered patches (LeucoPatch). Ann Transl Med 2018;6(Suppl 2):S126. doi: 10.21037/atm.2018.12.44
Platelet (L-PRF) Rich Fibrin in Diabetic Foot Ulcer with Osteomyelitis (Three Clinical Cases Report). Diseases 2018;6. doi: 10.3390/diseases6020030. 